\section{Application of RFLP Analysis to Genetic Linkage Mapping in Peaches}

\author{
L. Eldredge, R. Ballard, W.V. Baird', and A. Abbott \\ Department of Biological Sciences, Clemson University, Clemson, \\ $S C 29634-1903$
}

\author{
P. Morgens, A. Callahan, and R. Scorza \\ Appalachian Fruit Research Station, Agricultural Research Service, U. S. \\ Department of Agriculture, Kearneysville, WV 25430
}

\section{R. Monet \\ INM Centres de Recherches de Bordeaux, 33883 Villenave D'Ornon Cedex, France}

Additional index words. Prunus persica, restriction fragment length polymorphism, genome mapping

\begin{abstract}
Peach [Prunus persica (L.) Batsch.] is considered the best genetically characterized species of the genus Prunus. We therefore used it as a model in our study of the genome organization in Prunus by means of restriction fragment length polymorphisms (RPLPs). Initial results indicated that $60 \%$ of cloned DNA sequences examined occur at low copy number within the peach genome. After selecting and examining these sequences, polymorphisms sufficient for RPLP mapping were found. We determined that $» 33 \%$ of our cDNA clones and $20 \%$ of our genomic clones detected RPLPs among peach cultivars. Analysis of RPLP segregation in two families, both of which segregate for known morphological characters, revealed segregation in 12 RFLP markers for one family and $\mathbf{1 6}$ for the other. Although we have not detected linkage between RFLP and morphological markers, preliminary analyses indicate possible linkage between two RPLP markers.
\end{abstract}

Traditionally, the Rosaceae are divided into four well-defined subfamilies. One subfamily, the Prunoideae, is characterized by species that produce drupes as fruits and contains several important fruit tree species, such as peach/nectarine, within the genus Prunus.

Although Prunus is an important genus, little is known about the genome structure and organization of its members. To date, peach is considered the best genetically characterized species of the genus (Mowrey et al., 1990). Although no cytogenetic markers have been identified for peach, $\approx 35$ morphological (Monet, 1989) and biochemical (Arulsekar et al., 1986) traits have been described, with two pairs of markers showing linkage (Hesse, 1975; Monet et al., 1985; S.A. Mehlenbacher, personal communication). In addition, heritability has been estimated for another 20 traits (Monet, 1989). However, few monogenic (or qualitative) traits have been incorporated into individual lines to facilitate genetic studies. This underscores the extent to which the genetics of peach is still poorly understood.

Received for publication 3 June 1991. Accepted for publication 10 Sept. 1991. We thank J. Belthoff for editorial comments. This research was supported in part by funds from the South Carolina Agricultural Experiment Station Project 1310 and the National Science Foundation - R11-8922165. The cost of publishing this paper was defrayed in part by the payment of page charges. Under postal regulations, this paper therefore must be hereby marked advertisement solely to indicate this fact. 'Department of Horticultural Sciences.
Tremendous advances have been made in understanding the biology of simple and complex organisms through the development and use of genetic linkage maps (e.g., E. coli, Salmonella, yeast, Drosophila, Caenorhabditis). Traditionally, the development of complete linkage maps requires the identification of hundreds of single-gene mutations that govern easily scored phenotypic traits, and the availability of individuals from a segregating population such as an $\mathrm{F}_{2}$ or backcross. The long generation time in tree species severely limits the use of traditional and $(\mathbf{C})$ a highly repeated sequence probe. methods for genetic mapping. Molecular genetic approaches, however, enable one to rapidly produce highly saturated maps from existing crosses. One such technique examines the inheritance of RFLPs. Differences in fragment lengths are consequences of heritable changes in the DNA sequence structure. Because RFLPs behave in a strict Mendelian fashion and can be identified by molecular hybridization when plants are very young, these molecular markers are ideally suited to genetic map construction. In higher plants, most mapping efforts have been restricted to herbaceous plants (see, for example, Bonierbale et al., 1988; Helentjaris et al., 1986; Landry et al., 1987; Tanksley et al., 1988).

We are extending the use of RFLP mapping methods Prunus spp., beginning with the development of a genetic map in peaches. In this paper, we present initial observations on the level of DNA fragment polymorphism in peach cultivars and demonstrate segregation of RFLP markers in specific peach families (parents and offspring).

Plant material. Prunus leaf samples collected from orchards at Clemson Univ. included: 'Ruby Almond', 'Caramel Almond', peach $x$ [P. davidiana (Carrière) Franch], $\mathrm{S}$ x R 185 peach $x$ almond, NCA 10254 peach $\mathrm{x}$ almond, 'Springcrest', 'Babygold \#5', 'O'Henry', 'Carolina Red', 'Cresthaven', 'Stoneyhard', 'Redglobe', 'Ryan's Son', and 'Hakuto'. Leaves from 78 individuals in segregating populations (parents and offspring) from the Appalachian Fruit Research Station in Kearneysville, W.Va. (hereafter referred to as the WV families) and 27 individuals from the INRA Centres de Recherches de Bordeaux, Bordeaux, France (hereafter referred to as the French family) were used for linkage map construction.

DNA isolation and library construction. Genomic DNA was isolated from leaf tissue using the procedure of Rogers and Bendich (1985), slightly modified to increase DNA yield. Modifications included grinding leaf tissue with sand and increasing the amount

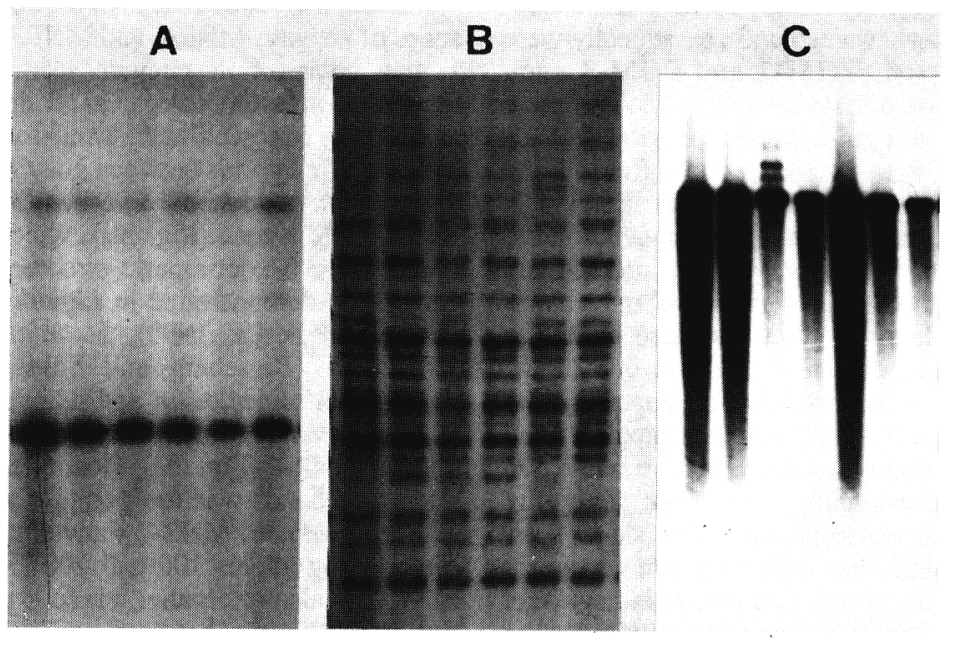

Fig. 1. Southern hybridization patterns of three types of random genomic inserts of peach detected by autoradiography: (A) a low-copy sequence probe, (B) an interspersed-repeated sequence probe, 

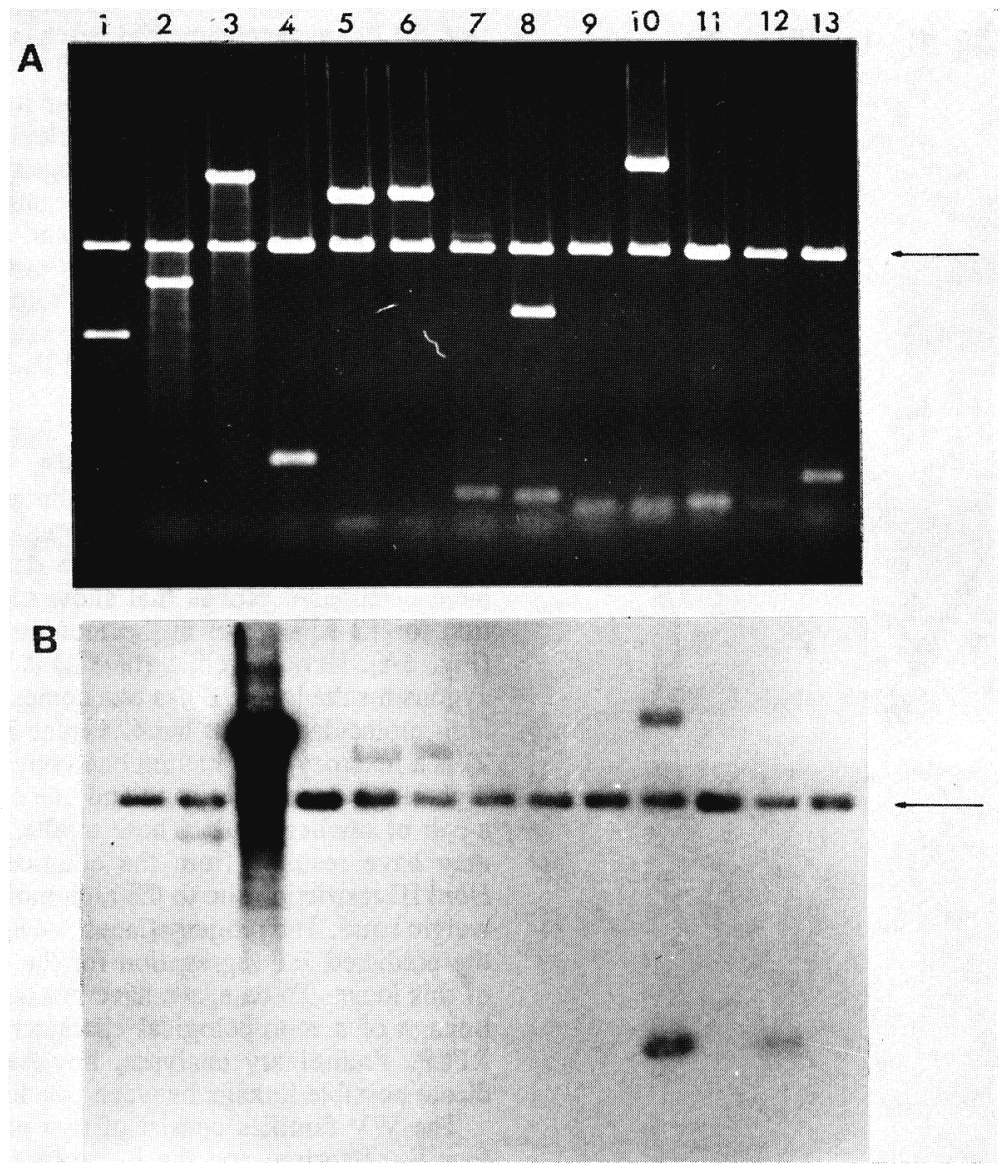

Fig. 2. (A) Eco RI digested random genomic peach clones electrophoresed through a $0.8 \%$ agarose gel. (B) Southern hybridization pattern of random genomic clones shown in (A) detected by autoradiography using nick-translated genomic peach DNA as a probe. Clones in lanes 1-3 were shown by previous analysis to carry low-copy, interspersed-repeated, and highly repeated sequences, respectively, and were used as standards to judge the copy number of unknown clones. The arrow denotes the position of the pUC8 plasmid used to internally standardize the loadings.

of leaf tissue and volumes of solutions, but keeping the original ratios.

Probes for RFLP analyses were of two types: 1) randomly selected genomic clones and 2) cDNA clones. Genomic libraries were prepared from the peach cultivars Blake and Bicentennial in the plasmid pUC8 (Messing, 1983), by digesting total DNA with the restriction enzyme Eco RI following the suplier's suggestions (Promega Biotech, Madison, Wis.). Plasmids carrying inserts were used to transform the bacterial host, a JM83 strain of E. coli (Maniatis et al., 1982). cDNA libraries were constructed in the vector Lambda Zap (Stratagene, San Diego) following Gubler and Hoffman (1983) and Morgens et al. (1990), except that doublestranded cDNAs were eluted over NENsorb (DuPont, Wilmington, Del.) columns, according to the manufacturer's instructions, before ligation to the vector. Three cDNA libraries were made from fruit RNA of the following cultivars: 1) 'Suncrest' harvested 30 days after bloom, 2) 'Loring' harvested between 5 and $20 \mathrm{~N}$ of fruit firmness, and 3) selection 612615 harvested at 140 days after bloom. These cDNA libraries were screened by differential hybridization; the nine timating copy number of each insert being screened. Autoradiography was carried out by placing filters in cassettes equipped with one Cronex Lightning Plus intensifying screen (DuPont). Kodak X-OMAT XAR-5 X-ray film was placed on the hybridized filters and cassettes were placed at $-80 \mathrm{C}$ for 2 - to 10 day exposures (depending on the strength of the hybridization signal). Following autoradiography, low-copy sequences were defined as those that showed little or no signal, interspersed-repeated sequences were those that gave faint but distinct signals, and highly repeated sequences showed very strong signals. Only clones judged to carry low-copy sequences were further analyzed as potential RFLP probes.

Detection of RFLPs. Genomic DNA from various cultivars was digested with several restriction enzymes, including sir-base (Hind III, Eco R1) and four-base cutters (Sau 3A, Hae III), and samples of each were electrophoresed on a $0.8 \%$ agarose gel for $\approx 16 \mathrm{~h}$ at $45 \mathrm{~V}$. Phage $\lambda$ DNA digested with Hind III was included as a molecular weight marker. Gels were treated and blotted onto nylon membranes (Southern, 1975) and membranes were hybridized with either prescreened genomic DNA or cDNA probes. To prepare the probes, recombinant plasmids were purified and digested to release the inserts, which were then isolated by electroelution from agarose gels (Maniatis et al., 1982). Genomic probes were either nick translated (Maniatis et al., 1982) or random primed (Feinberg and Vogelstein, 1983) to incorporate the radioactive signal. Isolated cDNA inserts were random primed using a kit from BRL (Gaithersburg, Md.). Filters were hybridized as previously described. Following autoradiography, filters were stripped of the radioactive probe for reuse by shaking gently in a $55 \%$ formamide, $2 \mathrm{x}$ SSPE $(0.15 \mathrm{M} \mathrm{NaCl}, 0.01 \mathrm{M}$ sodium phosphate, $0.001 \mathrm{M}$ EDTA, pH 7.4), $1 \%$ sodium dodecyl sulfate (SDS) solution at $65 \mathrm{C}$ for 45 to $90 \mathrm{~min}$ followed by a 1-min rinse in $0.1 \times$ SSC $(0.15 \mathrm{M} \mathrm{NaCl}, 0.015 \mathrm{M}$ trisodium citrate, $\mathrm{pH} 7.0$ ) and $0.1 \%$ SDS.

Our long-term objective is to obtain a highresolution RFLP map of the peach genome. To begin preliminary work toward this goal, a shotgun plasmid library of restriction-digested genomic peach DNA and a cDNA library from developing fruit were prepared to obtain a collection of clones to be used as probes in Southern hybridization analyses. Initially, clones were randomly chosen from the genomic plasmid library, and their inserts were used as probes to determine the proportion of clones in the library that had inserts of low-copy sequences. Clones carrying low-copy, interspersed-repeated, and highly repeated sequences were identified (Fig. 1). From these initial screenings, we estimated that $60 \%$ of 32 clones carried lowcopy sequences. Because $40 \%$ of clones carried sequences of little use in our analyses (i.e., interspersed-repeated and highly repeated sequences) a prescreening method was used to eliminate clones carrying repeated sequences. After prescreening, only clones 
7
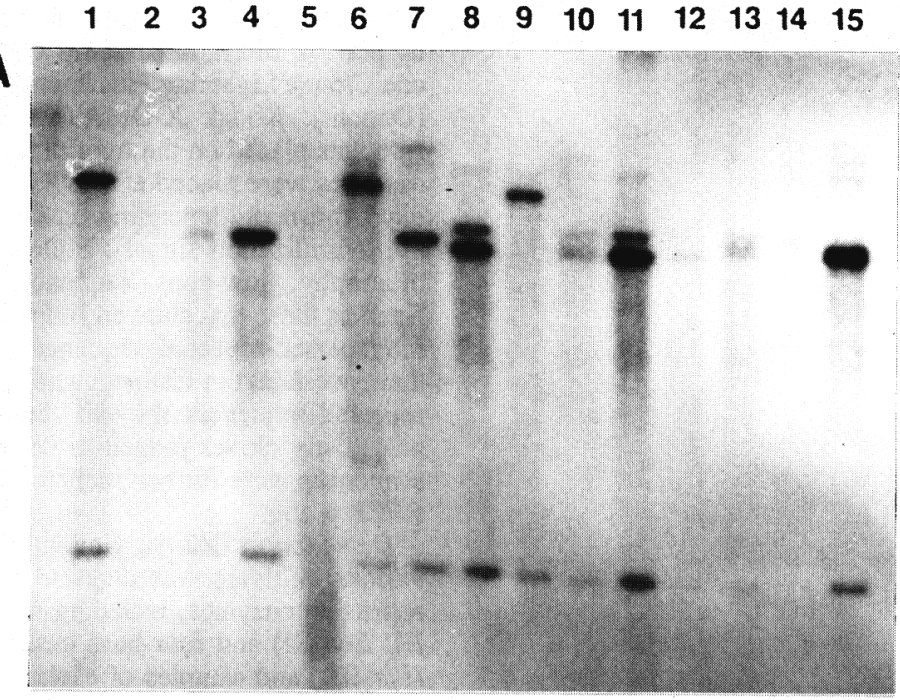

B

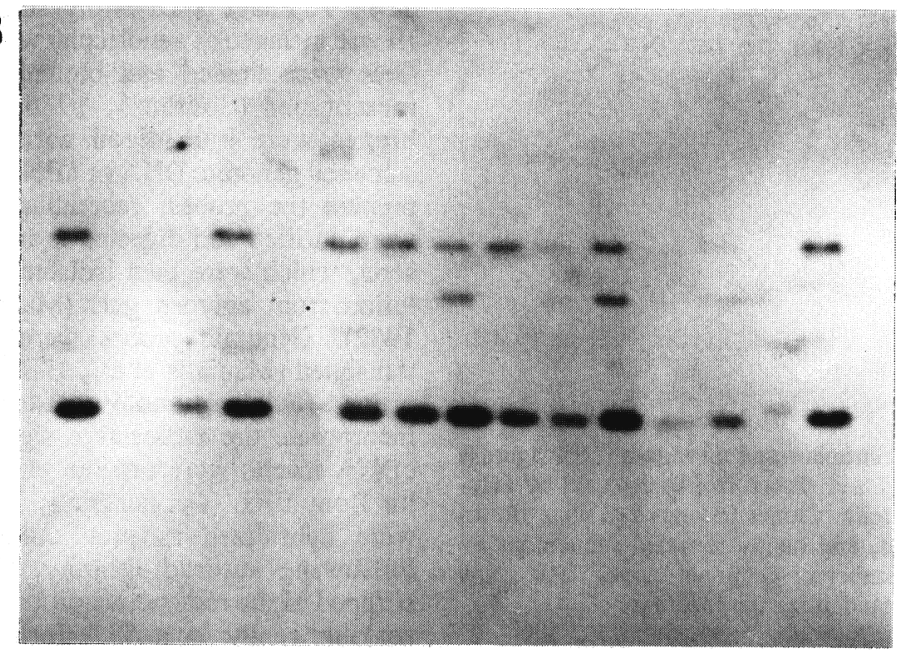

Fig. 3. (A, B) Southern hybridization patterns of two cDNA probes of peach detected by autoradiography. Genomic DNA of each was digested with Hind III and probed with either pch 103 (A) or pch 205 (B). Lane 1, 'White Glory'; lane 2, RRL-2N, lane 3, 174-RL; lane 4, 'Marsun'; lane 5, 'Davie II Dwarf'; lane 6, 'NC Pillar'; lane 7, 'Honey Gold'; lane 8, 'Redskin'; lane 9, 'NJ Pillar'; lane 10, 77119; lane 11, 'Armking'; lane 12, P19-11; lane 13, 77017; lane 14, 'Mission Almond' [Prunus dulcis (Mill.) D.A. Webb]; and lane 15, P. davidiana.

judged to be low-copy were further analyzed as potential RFLP probes (Fig. 2).

Previous isoenzyme studies suggest that the genetic base of peach is fairly narrow and that enzyme polymorphisms are quite rare (Durham et al., 1987; Mowrey et al., 1990). Therefore, initial efforts to generate an RFLP map were directed at assessing the extent of DNA polymorphism in peach cultivars. Four of 23 probes detected polymorphisms in the various cultivars, suggesting that the degree of polymorphism was sufficient for RFLP mapping. This degree of polymorphism was not as high as that detected in interspecific comparisons, where we estimated the level of polymorphism to be $>50 \%$ (i.e., 13 of 25 using Hind III). However, to avoid problems of map compression evident in interspecific crosses (Paterson et al., 1990), we worked only with crosses within $P$. persica.
Because cDNA clones represent sequences that are spatially and temporally regulated in tissues from which template RNA was isolated, they are ideally suited for investigating levels of polymorphism in genes or gene-flanking regions. We isolated nine cDNA clones that were complementary to genes differentially regulated during peach fruit development (Callahan et al., 1991). When used to screen for RFLPs among a variety of peach and almond cultivars and a peach $\mathrm{x}$ almond hybrid, three of the nine clones detected RFLPs among the peach cultivars. Only one clone did not detect an RFLP between the peach and almond cultivars. Of the nine clones, one represented a small repetitive family of related genes, one represented a small family of genes (perhaps 10 ), and the remaining seven represented one to three related genes each. Our analysis in- dicated that $\approx 33 \%$ of cDNA clones may detect RFLPs among commercial peach cultivars (Fig. 3).

Because one of the goals of our research was to link RFLP characters to agriculturally important morphological traits, progeny from peach crosses that exhibited segregation for both morphological characters and RFLP markers were necessary for map construction. Families that segregate for morphological traits need to be analyzed to determine the extent of segregation of RFLPs within these individuals.

Individuals resulting from the 'Jalhousia' $x$ 'Summergrand cross (i.e., the French family) showed segregation for three morphological characters: peach shape, pollen fertility, and peach/nectarine. To date, we have discovered probes that show segregation for 12 RPLP loci in the French family (Fig. 4A). Here, parent 1 (lane 1) is homozygous for the locus; it has two copies of the high molecular weight band. Parent 2 (lane 2) is a heterozygote, having one copy of the high molecular weight band and one copy of a pair of smaller bands. These smaller bands may have resulted from the addition of a Hind III restriction site to the high molecular weight band. The progeny (lanes 3-13) show the predicted 1:1 segregation for the alleles of this locus. To date, we have not detected linkage of a morphological character to an RFLP. Preliminary analyses, however, indicate possible linkage between two RFLPs.

The WV families consist of two parents, four $F_{1}$ offspring, and the $F_{2}$ progeny from the self-fertilized $F_{1}$ individuals. Individuals within this family show segregation for the genetic loci that influence tree shape and size. We have discovered probes that show segregation for 16 RFLP loci in this family. Figure 4B illustrates the segregation of an RFLP locus in one WV family, where the parents (lanes 1 and 2) are each homozygous at the RFLP locus, but each for a different allele. As expected, the $F_{1}$ individual (lane 3 ) is heterozygous for the alleles at this locus, inheriting one copy from each parent, and the $\mathrm{F}_{2}$ progeny (lanes 4-14) show the expected $\mathrm{F}_{2}$ segregation classes for the two alleles. We detected seven probes that showed polymorphism in both the French and WV families, allowing us to combine the mapping information from the data sets of these unrelated individuals. We used MAPMAKER (Lander et al., 1987) to statistically evaluate our data for linkage.

In conclusion, we demonstrated that peach displays sufficient DNA polymorphism to allow the construction of a molecular genetic map. This map will serve as a foundation to study genome organization and evolution in other Prunus spp.

\section{Literature Cited}

Arulsekar, S., D. Parfitt, and D. Kester. 1986. Comparison of isozyme variability in peach and almond cultivars. J. Hered. 77:272-274.

Bonierbale, M.W., R.L. Plaisted, and S.D. Tanksley. 1988. RPLP maps based on a common set of clones reveal modes of chromosomal evo- 

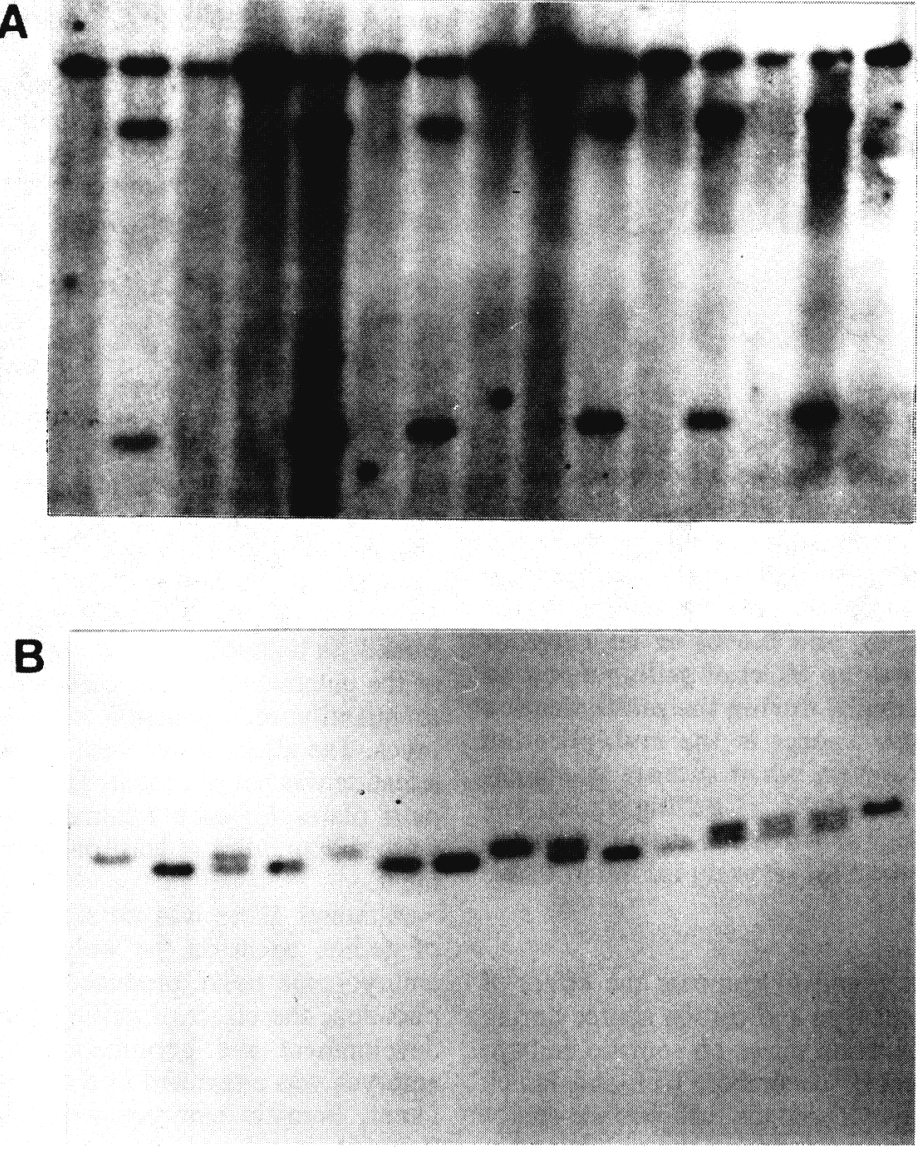

Fig. 4. (A, B) Southern hybridization patterns of polymorphic probes of peach detected by autoradiography. Genomic DNA was digested with Hind III and probed with either B2A10 (A) or B4F12 (B). (A) French family: lane 1, 'Jalhousia'; lane 2, 'Summergrand'; and lanes 3-15, F plants. (B) WV family: lane 1, 'NJ Pillar'; lane 2, 77119; lane 3, $\mathrm{F}_{1}$ plant, and lanes 4-15, $\mathrm{F}_{2}$ plants produced by self-pollinating the $F_{1}$.

lution in potato and tomato. Genetica 120:10951103.

Callahan, A., R. Scorza, P. Morgens, M.S. Mante, J. Cordts, and R. Cohen. 1991. Breeding for cold hardiness: searching for genes to improve fruit quality in cold hardy peach germplasm. HortScience 26(5):522-526.

Durham, R.E., G.A. Moore, and W.B. Sherman. 1987. Isozyme banding patterns and their use- fulness as genetic markers in peach. J. Amer. Soc. Hort. Sci. 112:1013-1018.

Feinberg, A.P. and B. Vogelstein. 1983. A technique for radiolabeling DNA restriction endonuclease fragments to high specific activity. Anal. Biochem. 132:6-13.

Gubler, U. and B.J. Hoffman. 1983. A simple and very efficient method for generating cDNA libraries. Gene 25:263-269.
Helentjaris, T., M. Slocum, S. Wright, A. Schaefer, and J. Nienhuis. 1986. Construction of genetic linkage maps in maize and tomato using restriction fragment length polymorphisms. Theoretical Applied Genet. 72:761-769.

Hesse, C.O. 1975. Peach, p. 285-335. In: J. Janick and J.N. Moore (eds.). Advances in fruit breeding. Purdue Univ. Press, West Lafayette, Ind

Lander, E.S., P. Green, J. Abrahamson, A. Barlow, M.J. Daly, S.E. Lincoln, and L. Newbure. 1987. MAPMAKER: An interactive computer package for constructing primary genetic linkage maps of experimental and natural populations. Genomics 1:174-181.

Lady, B.S., R.V. Kesseli, B. Farrara, and R.W. Michelmore. 1987. A genetic map of lettuce (Lactuca sativa L.) with restriction fragment length polymorphism, isozyme, disease resistance and morphological markers. Genetics 116:331-337.

Maniatis, T., E.F. Fritsch, and J. Sambrook. 1982. Molecular cloning: A laboratory manual. Cold Spring Harbor Laboratory, Cold Spring Harbor, N.Y.

Messing, J. 1983. New Ml3 vectors for cloning. Methods Enzymol. 101:20-78.

Monet, R., Y.-Bastard, and B. Gibault. 1985. Etude genetique et amelioration des pechs plates. Agronomic 5:727-731.

Monet, R. 1989. Peach genetics: Past, present and future. Acta Hort. 254:49-57.

Morgens, P.H., A.M. Callahan, L.J. Dunn, and F.B. Abeles. 1990. Isolation and sequencing of cDNA clones encoding ethylene-induced putative peroxidases from cucumber cotyledons. Plant Mol. Biol. 14:715-725.

Mowrey, B.D., D.J. Werner, and D.H. Byrne. 1990. Inheritance of isocitrate dehydrogenase, malate dehydrogenase, and shikimate dehydrogenase in peach and peach $\mathrm{x}$ almond hybrids. J. Amer. Soc. Hort. Sci. 115:312-319.

Paterson. A.H.. J.W. DeVema. B. Lanini. and S.D. Tanksley. 1990. Fine mapping of quantitative trait loci using selected overlapping recombinant chromosomes in an interspecies cross of tomato. Genetics 124:735-742.

Rogers, S.O. and A. Bendich. 1985. Extraction of DNA from milligram amounts of fresh, herbarium, and mummified plant tissues. Plant Mol. Biol. 5:69-76

Southern, E.M., 1975. Detection of specific sequences among DNA fragments separated by gel electrophoresis. J. Mol. Biol. 98:503-517.

Tanksley, S.D., L. Miller. A. Patterson. and R. Bernatzky. 1988. p. 157-173. In: J.F. Gustafson and R. Appels (eds.). Chromosome structure and Function. Plenum, New York. 